\title{
QUERO VOLTAR PARA A MINHA TERRA: ANGOLANAS E GUINEENSES DEPOIS DO DIPLOMA
}

\author{
Maria da Conceição Quinteiro ${ }^{l}$
}

\begin{abstract}
Resumo: As entrevistadas,oriundas de Angola e de Guiné Bissau,chegaram com um objetivo principal que era o de estudar, obter uma formação, para melhorar a própria vida e a da sua família, quando regressarem. Vieram por conta própria. Em São Paulo, as redes de solidariedade encontradas e as construídas, frágeis, (como as da terra de origem), para thes proporcionar a inserção social e econômica, que lhes facilitasse, a obtenção do objetivo principal. Trabalham em atividades informais, estudam,intermitentemente, em escolas privadas.Três experiências lhes causaram forte impacto, quando chegaram a São Paulo: a maneira desrespeitosa como são tratadas as pessoas idosas; a relação entre pais e filhos, a quase ausência de autoridade paterna; e o tipo de namoro dos jovens . Querem retornar depois do diploma. Não sabem quando isso será possível.
\end{abstract}

Palavras-chave: Mulheres angolanas e guineenses. Educação e trabalho em São Paulo.

\begin{abstract}
These interwied, from Angola and Guine Bissau, had a principal objective which was to study to obtain an education in order to improve their own lives and those of their families, when they return to their countries. When they arrive in São Paulo, they experience three forms of social impact related to differences in culture: The way older citizens are treated as insignificant; the manner in which parents are derespected by their children and finally, the casual nature of intimate relashionships among young people in the presence of their parents. These women come of their own accord and wish to study.However through the informal work they cannot afford to go private universities and are not sufficiently experience to access public ones.They hope to return to Angola and Guine Bissau with qualifications but do not know how long this process will take.
\end{abstract}

Keywords: Angolan and Guinean women. Education and work in São Paulo.

\section{O ENCONTRO DAS ENTREVISTADAS}

Este estudo tem origem num dos bairros mais emblemáticos da cidade de São Paulo, o bairro do Brás. Seu protagonismo advém de muitos fatores, desde o último quartel do século XIX, com a imigração subvencio-

Pesquisadora Associada do NUPPS - Núcleo de Políticas Públicas - USP-Universidade de São Paulo e do Centro de Estudos em Comunicação Social- CECS- Universidade do Minho, Portugal. E-mail: mquim@usp.br 
nada pelos governos e fazendeiros, sobretudo de italianos, para as fazendas de café do oeste paulista, mais a migração, também, de outras nacionalidades, para a indústria crescente, local, inclusive, da hospedaria dos imigrantes, que recebia os nacionais e os estrangeiros. Esse contingente imigracional estabeleceu residência no coração do Brás e nas adjacências.

O Largo da Concórdia, o centro do Brás, foi palco de manifestações artísticas, no famoso Teatro Colombo, que recebia frequentemente companhias de ópera e de teatro. Além disso, os trabalhadores da indústria trouxeram em sua bagagem as ideias socialistas e anarquistas e as difundiram a partir do Brás. Pode-se dizer que o Brás, graças aos imigrantes transformou-se numa torre de babel plana, e era no largo da Concórdia que todos se encontravam, palco de sociabilidades. As décadas passam, e nestas últimas, aquela vocação internacional ressurge com outros atores, novas qualidades. O teatro Colombo, do largo da Concórdia, foi demolido há muito tempo, restou um imenso cimentado, repleto de vendedores ambulantes, muito lixo e sujeira. A convivência entre eles, hoje, no Brás, estabelece-se a partir do trabalho. Há décadas deixou de ser local para residir, mas para a venda e compra de roupas, sandálias, calçados e bijuterias, mercadorias de pouca qualidade, além do trabalho nos salões cabelo de corte e arranjos afro. Compartilham deste mister imigrantes temporários e os que residem em SP. Os temporários, majoritariamente mulheres, compram as mercadorias para revendê-las em seus países, os residentes, também, em sua maioria mulheres, compram e despacham-nas para a suas famílias, para que estas as revendam lá na sua terra natal.

Pelas ruas do Brás pode-se verificar a estratificação social dos apoios aqui recebidos do imigrante. Os imigrantes, digamos, com bons apoios, já bem instalados e estabelecidos em São Paulo, trabalham nas inúmeras lojas do comércio atacadista e varejista, de roupas, calçados, brinquedos, setor alimentício, eletrônico e outros, de cariz popular. Ou seja, são apoiados por uma rede de solidariedade já estabelecida e com bom capital econômico. Os demais, aqueles com poucos apoios, ou sem nenhum, como os chegados ilegalmente, vendem suas mercadorias nas ruas e passeios, postas sobre um pano estendido no chão. Objetos geralmente advindos da indústria do contrabando, da falsificação roupas, bolsas, óculos, sandálias etc. Sempre atentos, em prontidão para se necessário, arrancar o pano do chão e correr do "rapa", a fiscalização contra o comércio ilegal.

Este espaço, próximo ao largo da Concórdia, no que se refere aos imigrantes africanos, do Senegal, Congo, Angola, Guiné Bissau, Cabo Verde, STP e Moçambique tornou-se o ponto de encontro, espaço de sociabilidade, em que amizades são construídas, pedidos de ajuda são atendidos, onde mantêm uma convivência aparentemente amistosa. Festas são programadas às sextas e aos sábados e nos bares é servido peixe à moda guineense, tertúlia que todos por ali e os que chegarem participam. Enfim, 
os imigrantes destas nacionalidades, conhecem e sabem que no Brás não se sentem sós, são sempre bem acolhidos. É um espaço de reconstrução de referências, com os novos vínculos somados aos antigos, e é uma maneira, também, de afirmar a sua identidade em terra estrangeira. No Brás deixam de ser africanos, para serem designados pela sua procedência: angolanas, guineenses, e nessa convivência fortalecem os laços de pertencer a uma cultura de um país distante.

ANGOlanas E GUINEENSES: A DECISÃo DE IMIGRAR...

Este trabalho vai abordar as mulheres angolanas e guineenses que imigraram para o Brasil para estudar. Há duas modalidades de estudantes, a resultante de convênios entre países e aquela que decorre da decisão de migrar sem nenhum apoio institucional. Os estudantes vindos pelos convênios entre países inscrevem-se no Programa Estudante Convênio Graduação- PEC-G, ou Pós-Graduação- PEC-PG, no país de origem. Estes programas atendem as solicitações de estudantes, geralmente dos círculos de relacionamento do poder político, econômico e social. O Governo brasileiro assegura a vaga em alguma universidade pública. Além disso, o estudante recebe um auxílio para se manter no Brasil, aproximadamente um salário mínimo, repassado pelas universidades, pago mensalmente. A procura pelo Brasil, entre outros fatores, foi estimulada pelas oportunidades que o país oferece aos países "pobres", veiculadas por porta-vozes brasileiros no estrangeiro. A criação da UNILAB- Universidade da Integração da Lusofonia Afro-brasileira, com campi no Ceará e na Bahia (2010), atesta as facilidades oferecidas pelo Brasil.

Conforme dados do Ministério das Relações Exteriores, o Brasil recebeu, entre os anos 2000 até 2013, 5.282 estudantes dos PALOPS, os países de língua portuguesa. De Angola foram recebidos, neste período, 583. E no ano de 2013, 53 alunos. Já os alunos da Guiné Bissau perfizeram nesses anos o total de 1336, e no ano de 2013,118 estudantes. Do total de estudantes vindos na modalidade conveniada, entre os anos 2000 a 2013, os angolanos perfizeram $11,05 \%$ e a Guiné Bissau 25,30\%, do total de estudantes vindos dos PALOPS.

O estudo, ora apresentado, contempla apenas as mulheres estudantes que migraram para estudar, contando apenas com os próprios recursos financeiros.

A decisão de migrar foi geralmente tomada em conjunto com suas famílias, pois almejam um aporte monetário futuro para benefício de toda a família. Tinham forte convicção das ofertas de oportunidades brasileiras de ascensão social. Por vezes, essa decisão também contou com a propaganda fácil e enganosa, de faculdades brasileiras de duvidoso ensino superior, que divulgam, sobretudo, em Luanda e Bissau, facilidades de ascensão so- 
cial, por módicas parcelas mensais. Migraram, por sua conta e risco, para estudar, trabalhar, ajudar a família e retornar com um diploma. ${ }^{2}$

Elas entram no Brasil, umas com visto de turista, outras com o de trabalho, matriculam-se em alguma faculdade privada e, com o comprovante, requerem o visto de estudante, anualmente renovado. Não há dados desta modalidade de estudantes, quantos são, quem são, sua origem, idades, homens, mulheres etc. Assim, para saber da sua existência, só é possível quando se faz um trabalho de pesquisa qualitativa, ir a campo, a partir de uma pessoa imigrante, consolidar e ampliar a rede de contatos, para fazer outros tantos, de modo a criar um universo de mulheres estudantes. Assim, desta maneira foi possível conhecer muitas guineenses e angolanas, com quem conversei para entender um pouco de suas vidas.

Elas nos contaram sobre suas vidas em sua terra natal. A composição da sua família, a relação entre os mais velhos e os mais novos, e entre mulheres e homens; a decisão de migrar e as expectativas quanto à migração. Também relataram o impacto na chegada, quanto à família e a relação entre os mais velhos e os mais novos, as representações que faziam do Brasil sobre as oportunidades de trabalho e de estudo, sobre as redes de solidariedade, a construção das sociabilidades e as estratégias utilizadas, não só para viver, como para permanecerem no Brasil.

São doze jovens entre 25 a 33 anos, seis residiam em Luanda (Angola) e seis em Bissau (Guiné). Com escolaridade equivalente ao ensino médio brasileiro, o que lhes permite ingressar no ensino superior, solteiras, residentes nos bairros periféricos da cidade de São Paulo. Imigraram num período de dez anos, sendo que as mais recentes estão concentradas no período de dois a cinco anos. Todas as entrevistadas trabalham como vendedoras, cabeleireiras, faxineiras e estudam, ou tentam estudar. Fazem inúmeros cursos em escolas de pouco gabarito, apenas uma faz um curso numa universidade privada melhor conceituada.

\section{PORQUE DECIDIRAM VIR PARA O BRASIL?}

Vieram para estudar e ajudar a família. Aliás, nesta decisão, a família tem papel importante, pois parece ser um projeto familiar um filho migrar para ajudar os pais e os demais familiares.

Todas, as entrevistadas, vieram para estudar, "para ter uma formação", não importa qual, para voltar com a chance de arranjar um emprego.

\footnotetext{
As faculdades privadas em Bissau e Luanda que fizeram propaganda enganosa são FATENE, EVOLUÇÃO e FACOL. Ofereciam cursos de enfermagem, serviço social, educação física, sistemas de internet/análise e desenvolvimento, gestão de tecnologia da informação, redes de computadores, processos gerenciais (gestão de empresas), marketing de infraestrutura etc.
} 
Levar um diploma representa para elas aquisição de uma posição social melhor individualmente, e também para a sua família.

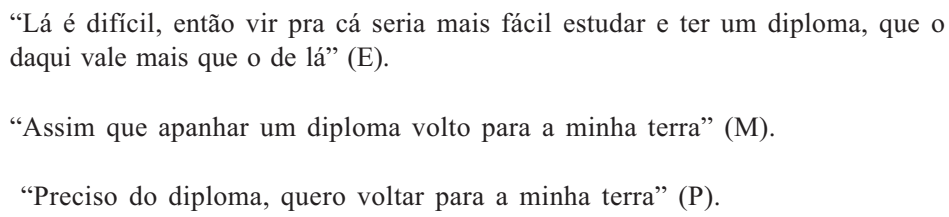

E no decorrer das entrevistas, outro objetivo vai se configurando, além do de estudar. Estudar não era o único objetivo. Também vieram para trabalhar. Necessitam de trabalho remunerado para custear a sua estada com as despesas, com o morar, o transporte, alimentação, pagar a faculdade e enviar mercadorias e/ou dinheiro para as suas famílias.

No Brás há transportadora de mercadorias para os países dos imigrantes ${ }^{3}$. É comum o envio de roupas, sapatos, utensílios de cozinha, sandálias havaianas e de outros tipos e brinquedos para o abastecimento das famílias e, principalmente para a revenda em Angola e Guiné, por um dos membros familiares.

Todas tinham algum contato no Brasil, como, aliás, é praxe nos processos migratórios a existência de redes de apoio no local de destino e, inclusive, no da origem. Necessitam estudar para ter uma formação e para ter o comprovante de estudante que garanta, junto à Polícia Federal brasileira, o visto de estudante para permanecer no Brasil. Nem todas estudavam no ato da entrevista.

\section{IMPACTOS À CHEGADA: ESTRANGEIRAS NUM MUNDO ESTRANHO}

Vamos contemplar elementos mais significativos das suas percepções. Não vamos considerar as especificidades culturais de cada grupo. De antemão sabemos, tanto em Angola como na Guiné-Bissau, da existência de inúmeras etnias, e que apesar da formação dos estados, da adoção de uma língua oficial, de uma religião e um corpo jurídico que normatiza a vida moderna em sociedade, se fizermos um estudo etnográfico, vamos encontrar peculiaridades que persistem advindas de situações anteriores.

Somente vamos nos ater a algumas das suas percepções e representações a partir do impacto quando da chegada em terras brasileiras, especificadamente na cidade de São Paulo.

Há inúmeros compradores, principalmente mulheres, vindas dos PALOPS, fazer compras para distribuição e revenda nos países de origem e em outros. Enormes volumes são despachados por essa transportadora sediada no Brás. 
À questão sobre como imaginavam o Brasil e São Paulo quando da decisão de imigrar para cá, conforme os seus relatos, todas sofreram grande impacto, pois a representação, que não é a realidade, é a realidade imaginada, estava muito aquém do esperado do país que escolheram para imigrar.

"Achava que era mais fácil... país grande, com indústrias... com muito emprego... na novela tudo maravilhoso... chega aqui, nada disso... na Guiné ninguém avisa que o Brasil não é o que dizia o governo, o que dizia a novela" (E).

"Achava que não tinha mendigo na rua, não tinha cachorro, que não tinha favela, não tinha pessoa pobre... que todo mundo era bonito... que não tinha essa violência. Quando cheguei fiquei até doente" (M).

"Na novela todo mundo bonito, todo mundo se abraça, todo mundo é alegre, até nas favelas têm casas lindas (L).

“Aqui é muita gente na rua e o que a gente via na novela e não é isso. .. só coisas de violência muito estranha ..lá não pode matar as pessoas.. aqui já vi dois mortos... na rua é muita sujeira muita mesmo" (S).

Por coincidência todas representam o Brasil de acordo com as informações recebidas das novelas. A realidade imaginada veiculada pela ficção exerce fascinação tão poderosa que nenhuma delas, nem seus familiares, nem os contatos já instalados no Brasil, foram capazes de fazer a distinção entre a ficção e o real. E assim, que país melhor para imigrar? A constatação da realidade deixou-as frustradas, porém, continuam vivendo em São Paulo e tocando a vida. Essa frustração, entre o que é e o imaginário, também foi detectada, entre mulheres portuguesas, na década de 1950, que imigraram, e acreditavam que iriam encontrar no Brasil a "árvore da pataca". ${ }^{4}$ Talvez, $\mathrm{o}$ imaginário funcione como a maneira de acreditar num futuro melhor e como alavanca para a decisão de imigrar. Na década de 50 do século $\mathrm{XX}$, ainda não haviam novelas massivamente disseminadas, apenas os relatos de várias gerações, no entanto, aquelas mulheres lusas,vieram para a terra prometida.

Outro impacto revelado pelas entrevistadas diz respeito à concepção de família e ao relacionamento entre os jovens e os idosos, seja no seio familiar seja em âmbito da sociedade. Na convivência com os da terra perceberam a distância entre a concepção de família, na qual foram socializadas e ainda continua vigente em sua terra natal, com a encontrada aqui na

\footnotetext{
Imaginário social que aponta o Brasil como a terra prometida, sonhada por todos, onde haveria felicidade, pouco trabalho, uma vida boa e, nas ruas, a "árvore da pataca", bastava abaná-las que as moedas caiam. Tal era a prosperidade e a bonança pelas terras brasileiras. Ver Quinteiro, MC, Portuguesas para o Brasil: o sonho sonhado. Actas do Congresso Feminista, 2008, Funchal, Portugal, 2010
} 
cidade de São Paulo. Tanto angolanas como guineenses entendem família não como o núcleo básico composto de pais e filhos, como na moderna família nuclear. Para elas a família engloba gerações que constituem esse conjunto familiar ao qual pertencem, e demais membros que moram, se não sob o mesmo teto, próximos uns dos outros: pais, irmãos, avós, tios, primos, sobrinhos e netos. Parece que nesta concepção de família extensa persistem traços do sistema clânico tradicional às várias etnias, como por exemplo, os Bijagós da Guiné, ${ }^{5}$ cuja organização familiar obedece a categorias de idade. Tanto é assim que, angolanas e guineenses, ressaltam o impacto que tiveram ao constatarem que as pessoas mais velhas aqui, em São Paulo, não são respeitadas como lá, sejam da família ou não.

\begin{abstract}
"Os mais velhos têm autoridade sobre nós, para não fazer coisa errada. Os velhos podiam dar conselhos, chamar atenção da gente. Lá a gente considera os velhos uma dádiva de Deus que você tem que respeitar." (M).

"Aqui a diferença é no tratamento, eles jogam os velhos na rua. não respeitam, não dão atenção" (P).

"Os mais velhos aqui parece que não existem. É difícil ver no metrô alguma pessoa velha... eles faz de conta que dorme pra não dar o lugar pras pessoas idosas" (L).
\end{abstract}

"Os mais velhos é como se fosse um museu, eles guardam tudo que foi feito antes de nós, então eles são uma bênção e agente tem que respeitar" (B).

Outra maneira de conceber o relacionamento familiar foi apontada pelas entrevistadas como estranho para elas, que é a ausência de autoridade dos pais e mães brasileiros, em contraste com a existente em Angola e em Guiné, para com os filhos.

"Lá não pode filhos ficar namorando na frente de mãe e pai, se beijando... aqui os filhos não obedecem o pai nem mãe e nem os mais velhos" $(Z)$.

"Pai e mãe tem medo dos filhos, não dão educação, não dão conselhos, não ensinam... os filhos só querem o sustento dos pais... que os pais fazem tudo..." $(\mathrm{H})$.

"Eu vejo nos vizinhos que as mães não param, só trabalham e os filhos e as filhas só gastam. Se tem algum dinheiro é só pra eles... lá não é assim, a gente se ajuda e respeita os pais, os avós, os tios" (P).

Ver: "Por entre as Dórcades Encantadas: Os Bijagós da Guiné-Bissau. Ed. Terceira Margem, São Paulo, 2000. A autora mostra em sua pesquisa que apesar da "missão civilizadora" do capital, que conduz a um estilo de vida ocidental, ainda persiste outra visão do mundo e valores, digamos tradicionais, que amalgama o modo de ser, de pensar e de agir dos Bijagós. 
VOU FICAR, NÃO SEI QUANDO VOLTAR PARA A MINHA TERRA

Durante as entrevistas, outros objetivos e maneiras de contornar a ausência de um visto definitivo de permanência, aos poucos ampliaram o universo de necessidades destas mulheres. Não só desejavam estudar para ter um diploma, como. também precisavam de trabalhar e, parece que com a vontade de retornar já arrefecida, conjecturavam estratégias para garantir a sua permanência nestas terras.

Os impactos cruciais do início em relação à representação que faziam do Brasil, a maneira como são tratados os idosos, a ausência da autoridade paterna com os filhos, a convivência com os da terra, fizeram-nas se adaptar às regras deste país. Ainda querem voltar para as suas terras, porém, ainda têm um longo caminho a trilhar.

As estratégias vão aos poucos sendo explicitadas. A primeira é a de obter o visto de estudante, maneira de ampliar o prazo de permanência com renovação garantida durante a realização do curso. Diante dessa inferência, seria o caso de perguntar se seria estudar o objetivo principal?Parece que é, embora esteja difícil qualquer conclusão.

Outras estratégias podem facilitar os seus objetivos, como por exemplo, quando o dinheiro auferido com o trabalho é insuficiente para morar, comer e estudar. Uma entrevistada disse que vai tentar obter financiamento do FIES, (fundo de financiamento estudantil para cursos profissionalizantes e superior). "Tou pensando pedir para o Fies o pagamento da escola... não sei se vou conseguir, mas vou tentar" (E).

Outra disse que vai à Cáritas, entidade da Igreja Católica, responsável por encaminhar às autoridades competentes os documentos dos imigrantes que pedem refúgio. E com o status de refugiada terão algumas regalias em terras brasileiras, como por exemplo, não mais precisar apresentar o comprovante de estudante para obtenção do visto de residência.

\footnotetext{
"Tenho um amigo duma entidade social que me disse recorrer à Cáritas pra pedir refúgio."... tou desempregada, não posso pagar a escola, não posso apresentar o comprovante pro visto de estudante... “(H).
}

Há ainda, a possibilidade de contrair matrimônio com um brasileiro para residir sem problemas no Brasil, ou ainda, ter filhos. Possibilidades, que as entrevistadas não parecem entusiasmadas em consegui-las. Pois, alegam que sofrem preconceito. Dizem que os brasileiros não se interessam por elas. Já ao contrário, os homens migrantes africanos, muitos, casaram com brasileiras. E os africanos, seus conterrâneos inclusive, preferem as brasileiras. Elas sentem que são alvo do preconceito social, uma vez que não são ricas e têm que trabalhar muito para seu sustento 
"Meu colega do salão, do Congo, casou com uma brasileira... já tem um filho, não tem mais problemas de visto." (P).

"Eu tenho um namorado, é também angolano... ele não quer saber de ter filhos, diz que ainda é cedo, temos que arranjar a nossa vida. Ter primeiro a permanência." (Z).

Conforme dizem as entrevistadas, o preconceito desaparece se a mulher for "rica", tiver meios e condições de vida melhores que as deles. Neste sentido, o preconceito é atravessado pelo recorte de gênero e também pelo de situação econômica da mulher.

Quanto ao preconceito de cor, pensavam que o no Brasil ele não existisse, que todos, brancos e negros, convivessem em harmonia sem distinções. Alegaram que são discriminadas.

\footnotetext{
"Minha sobrinha de 15 anos retornou para Bissau, ficou oito meses aqui, era xingada na escola, remedavam" (C).

"Nas novelas todos se dão bem, mulheres negras casam com homens brancos, todos vivem bem, não tem pobreza, mas não é assim”(A).
}

Estas angolanas e guineenses ainda não alcançaram o objetivo de fazer um curso. Mas, apesar da constatação de que a representação sobre o Brasil não corresponde ao que vivem, persistem em ficar, embora, por outro lado, querem retornar de vez para sua terra natal.

Apesar das dificuldades que encontram numa terra estranha, são persistentes, inventam estratégias para permanecer em São Paulo. Mas o desejo recorrente, que não as deixa em paz, é conseguir uma formação,ainda que demore anos ou seja, um diploma de curso superior para depois, voltar para as suas terras. Sabe-se lá quando.

\section{REFERÊNCIAS BIBLIOGRÁFICAS}

FREITAS, Maria Sônia. Presença Portuguesa em São Paulo. Imprensa Oficial, São Paulo, 2006. LOBO, Eulália M.L. Imigração Portuguesa no Brasil. Editora Hucitec. São Paulo, 2001.

QUINTEIRO, Maria da Conceição. "Portuguesas para o Brasil: o sonho sonhado". Quem tem medo dos feminismos? Actas do Congresso Feminista 2008. p148 -163. Ed. Nova Delphi.Funchal 2010 .

SANTOS, A.L. "Angolanos em São Paulo: socialização, rede familiar e suas histórias de vida e de luta" Dissertação de Mestrado. Programa de Pós-Graduação em Sociologia da FFLCS. Universidade de São Paulo, 2006. 
SANTOS, Orlando. O Dilema das Zungueiras em Luanda: percepção acerca das representações sociais do seu quotidiano. Universidade Agostinho Neto. Luanda: Mímeo, 2010.

SILVA, de Melo Dilma, Por entre as Dórcades Encantadas - os Bijagós da Guiné-Bissau. São Paulo: Terceira Margem, 2000.

Travessia - Revista do Migrante - Centro de Estudo Migratórios - CEM - ano XXIV, n 68/junho 2011 - Pastoral do Migrante, Missão Paz, São Paulo, Brasil.

Travessia - Revista do Migrante - Migrações no Brasil - CEM - Centro de Estudos Migratórios, Ano XIII, no 36 janeiro/abril, 2000. Missão Paz, São Paulo, Brasil.

VARGEM, Alex André "A invisibilidade e o abandono dos imigrantes e refugiados africanos no Brasil" Trabalho apresentado no Seminário Imigração Internacional Recente para o Brasil. Núcleo de Políticas Públicas da Universidade de São Paulo, agosto de 2015. 